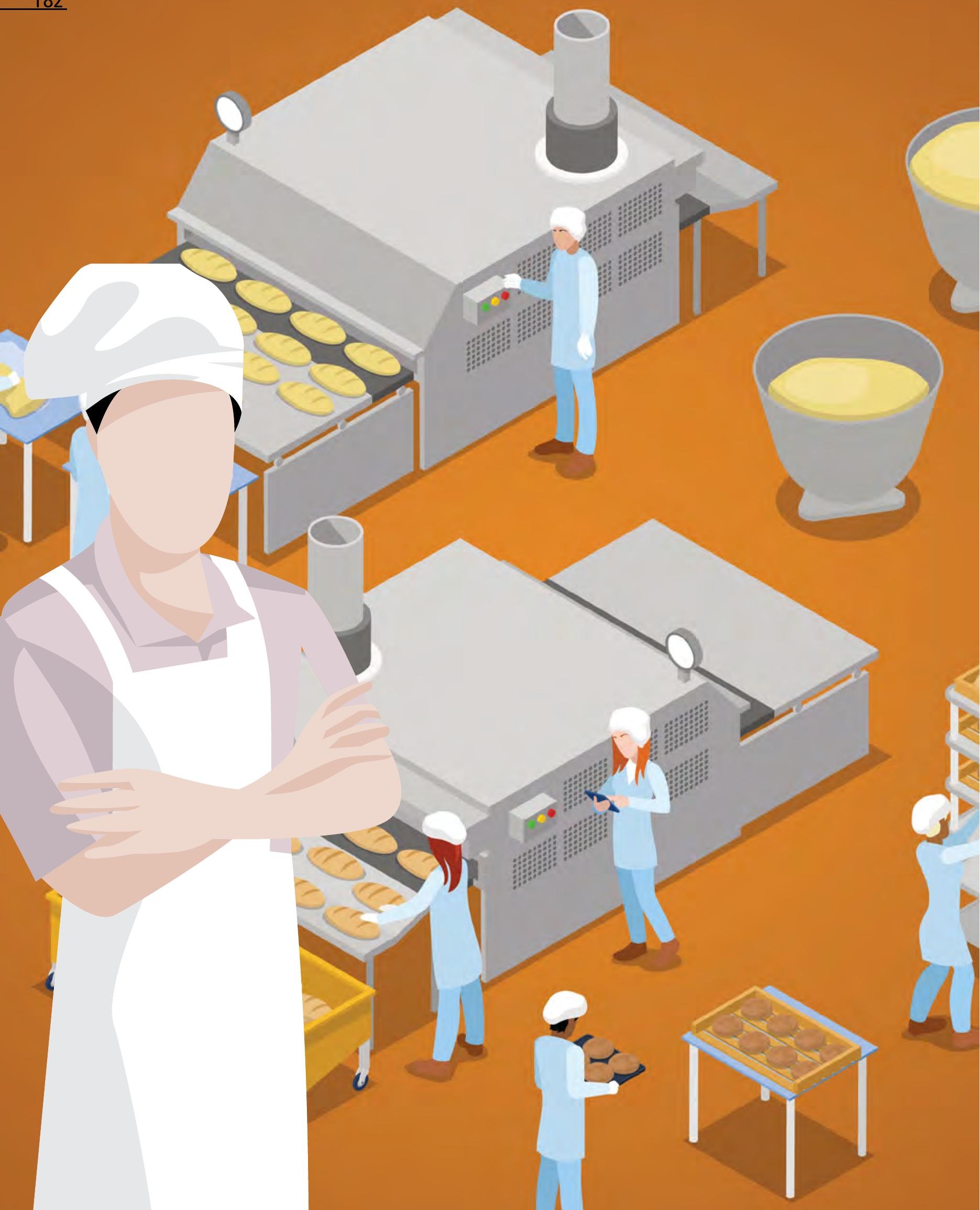

B. Téc. Senac, Rio de Janeiro, v. 43, n. 3, p. 182-201, set./dez. 2017. 
* Mestrando em Gestão Social, Educação e

Desenvolvimento Local no Centro Universitário Una. Gastrólogo, Especialista em Gestão e Ensino Superior, Professor nas Faculdades Promove. Belo Horizonte, Minas Gerais, Brasil. E-mail: fredivino@yahoo.com.br.

*Professor/pesquisador do Programa de Pós-Graduação em Gestão Social, Educação e Desenvolvimento Local do Centro Universitário Una. Bacharel em Direito, Mestre em Administração pela Universidade Federal de Lavras (UFLA) e Doutor em Gestão Urbana pela Pontifícia Universidade Católica do Paraná (PUCPR). Belo Horizonte, Minas Gerais, Brasil.

E-mail: frederico.

figueiredo@prof.unibh.br.

Recebido para publicação em: 21.9.2016

Aprovado em: 27.6.2017

\section{POLÍTICAS PÚBLICAS DE} EDUCAÇÃO PROFISSIONAL COMO FERRAMENTA DE EMPODERAMENTO: O PROGRAMA PÃO ESCOLA NA PREFEITURA DE BELO HORIZONTE

\section{VOCATIONAL EDUCATION PUBLIC POLICIES AS AN EMPOWERMENT TOOL: THE PÃO ESCOLA PROGRAM IN THE CITY OF BELO HORIZONTE}

\section{POLITICAS PÚBLICAS DE EDUCACIÓN PROFESIONAL COMO HERRAMIENTA DE EMPODERAMIENTO: EL PROGRAMA PAN ESCUELA EN LA MUNICIPALIDAD DE BELO HORIZONTE}

\author{
Frederico Divino Dias* \\ Frederico de Carvalho Figueiredo**
}

\section{Resumo}

A educação profissional apresenta-se na dualidade entre promoção do empoderamento e treinamento para o mercado de trabalho. Este estudo teve por objetivo apresentar o Programa Pão Escola, da Prefeitura de Belo Horizonte, como política pública de educação profissional, relacionando-a com as teorias discutidas para determinar se corresponde a um recurso de caráter neoliberal ou uma política que estimula o processo de empoderamento. Por se tratar de um artigo de revisão teórica, conclui por propor a avaliação futura das dinâmicas educativas do programa com outras ferramentas de pesquisa.

Palavras-chave: Qualificação profissional. Educação. Empoderamento. Mundo do trabalho.

\section{Abstract}

Vocational education appears in the duality between empowerment and training for the labor market. This study aimed to introduce the Pão Escola Program, sponsored by the county of Belo Horizonte as a vocational training public policy, linking it to the theories discussed to determine whether it would correspond to a neoliberal resource or otherwise to a policy that stimulates 
the empowerment process. Because this is a theoretical review article, our conclusion is a proposal of evaluation in the future of the educational dynamics of the program by employing other research tools.

Keywords: Professional qualification. Education. Empowerment. World of work.

\section{Resumen}

La educación profesional se presenta en la dualidad entre promoción del empoderamiento y capacitación para el mercado de trabajo. Este estudio tuvo como objeto presentar el Programa Pan Escuela, de la Municipalidad de Belo Horizonte, como política pública de educación profesional, relacionándola con las teorías discutidas para determinar si corresponde a un recurso de carácter neoliberal o una política que estimula el proceso de empoderamiento. Tratándose de un artículo de revisión teórica, concluye por proponer la evaluación futura de las dinámicas educativas del programa con otras herramientas de investigación.

Palabras clave: Calificación profesional. Educación. Empoderamiento. Mundo del trabajo.

\section{Introdução}

Os autores Barbosa e Deluiz (2008) afirmam que os jovens na faixa etária de 15 a 24 anos, principalmente das camadas mais populares da sociedade, são os menos atendidos tanto no mundo escolar quanto no profissional. Em seu documento sobre as Tendências Mundiais de Emprego 2012, a Organização Internacional do Trabalho (ORGANIZAÇÃO INTERNACIONAL DO TRABALHO, 2012) reforça a mesma concepção, ao afirmar que, em 2011, cerca de 74,8 milhões de jovens nessa faixa etária estavam desempregados. A partir de fragilidades dos sistemas educacionais, como falta de apoio e redes de proteção, esse grupo encontra-se, na maioria das vezes, em estado de vulnerabilidade social. A dificuldade de inserirem-se no mundo do trabalho, a busca pelo primeiro emprego, o restrito acesso à educação e a inadequada qualificação profissional são algumas das dificuldades que encontram pelo caminho (BARBOSA; DELUIZ, 2008).

Para que tal grupo aumente sua participação na sociedade, a sua escolaridade e tenha a sua inserção e manutenção no mundo do trabalho garantidas, é necessária a adoção de diversas práticas que assegurarão o desenvolvimento igualitário dentro de determinada localidade (SILVA, 2014; SILVA; JUNG; VIEIRA, 2012). Essas práticas deverão ser propostas e adotadas pela própria 
sociedade civil, governos, Organizações não governamentais (ONGs), entre outras associações que visem claramente à melhoria da qualidade de vida em todos os sentidos - das pessoas mais necessitadas.

Atualmente, uma destas áreas de atuação que tem chamado a atenção, e é de extrema importância para toda a população, é a de relações de emprego às quais os trabalhadores estão expostos. Segundo os dados do ano de 2016 do Instituto Brasileiro de Geografia e Estatística (IBGE, 2016), a estimativa de desemprego médio na região metropolitana de Belo Horizonte subiu de $4,9 \%$, em fevereiro de 2015, para 7,2\%, em fevereiro de 2016, sendo que o grupo da faixa etária compreendida entre 15 a 24 anos teve aumentado o número de pessoas desocupadas de 49 mil para 68 mil em um ano.

A partir desses dados, alguns atores sociais (órgãos da administração pública, a título de exemplo) veem-se na obrigação de adotar medidas que diminuam estas taxas para elevar a qualidade de vida de sua população. Programas como Jovem Aprendiz, Primeiro Emprego e alguns cursos de qualificação e capacitação são alguns dos exemplos que atuarão diretamente nas relações de emprego e renda deste segmento da sociedade. A partir deles, jovens entre 15 e 24 anos aprenderão determinados ofícios e terão elevadas suas chances de inserção no mundo do trabalho. O presente estudo investigará cursos de qualificação profissional e suas relações com a educação dos trabalhadores.

Com a alta demanda da qualificação profissional e melhora da força de trabalho dos sujeitos, a Prefeitura de Belo Horizonte (PBH), por meio de três secretarias, oferta neste município o Programa Pão Escola (PPE), uma política pública do governo municipal que "visa a qualificação na área de alimento para estudantes da Rede Municipal de Ensino" (BELO HORIZONTE, 2011a). Tal programa oferece cursos de qualificação para jovens e adultos que estejam regularmente matriculados nas modalidades de ensino da Educação de Jovens e Adultos (EJA) e Floração ${ }^{1}$ por meio do sistema educacional do município.

Tendo por objetivo analisar se o PPE é uma política pública que - além de mera educação capitalista - pode estimular ou não o processo de empoderamento do discente por meio da qualificação profissional, o presente artigo apresentará dados do Programa para realizar uma análise comparativa com a bibliografia levantada - por meio de uma revisão de literatura e pesquisa documental - que buscou os conceitos pertinentes, como: a educação profissional, o empoderamento e as políticas públicas.

Dividido nas próximas cinco seções, o presente estudo apresentará o conceito de educação profissional tradicional (pautada pela formação capitalista que utiliza a capacitação como forma de elevação dos lucros empresariais), 
além da relação da educação e o empoderamento como contraponto à educação profissional tradicional. Em seguida, trata das políticas públicas - entre elas, as políticas educacionais -, demonstrando os dados coletados do PPE e a discussão dos mesmos à luz da bibliografia estudada. Por fim, apresentam-se as conclusões e indicações para o desdobramento das pesquisas sobre o tema.

\section{Educação profissional "tradicional"}

A divisão dos indivíduos dentro de uma mesma sociedade, de acordo com sua ocupação no mundo do trabalho, apresenta diferentes abordagens pelas diversas culturas e povos. Para os povos europeus, por exemplo, o pertencimento às corporações de ofício conferiu um lugar mais digno ao trabalho e à personalidade das pessoas. Já os povos anglo-saxônicos incorporavam ao sobrenome as profissões de seus antecessores, como Schöeler, sapateiro; Fischer, pescador, entre outros (FISCHER; FRANZOI, 2009).

Inseridos em uma sociedade com um modelo de acumulação de capital flexível, impulsionado pela reestruturação produtiva e novos avanços alcançados na gestão das empresas, Rocha-Vidigal e Vidigal (2012) afirmam que o mercado tornou-se mais competitivo e exigiu das empresas novos níveis de produtividade, o que, por consequência, demandou maiores investimentos em qualificação profissional, pois o mundo do trabalho agora anseia por um profissional preparado para lidar com as transformações, "obrigando-o a assumir uma nova forma de trabalho para se adequar às novas exigências do capital" (CARMO, 2015, p. 100).

Barbosa e Deluiz (2008) argumentam que o Brasil tem modernizado seus aparatos a partir das políticas neoliberais ${ }^{2}$ e, concomitante a isso, é necessária uma mobilização junto à classe dos trabalhadores para a elevação da escolaridade, preparo para enfrentar as exigências do mercado e uma melhora do sistema de formação por parte dos gestores.

O trabalhador, visto por Rocha-Vidigal e Vidigal (2012) como peça fundamental, depara-se com um mercado exigente e entende a real necessidade da adaptação e reciclagem de seus conhecimentos bem como de suas habilidades. É exigido pelo mundo do trabalho que ele tenha capacidade de autoaprendizagem, entendimento dos processos que o cercam, assim como a noção da observação, interpretação, tomada de decisão e avaliação dos resultados. Alves e Vieira (1995) apontam, ainda, ser de fundamental importância o domínio da linguagem técnica, a comunicação oral, a escrita, a habilidade dos trabalhos em grupo, a polivalência cognitiva e a versatilidade organizacional. 
As organizações passam a valorizar mais os trabalhadores com posicionamento crítico, criativo e pensante para lidar com o novo mercado
Segundo Steffen e Fischer (2008), cursos de qualificação profissional ofertarão uma nova combinação entre os saberes e a correta ligação entre a teoria e a prática, além de facilitar o enfrentamento, por parte dos trabalhadores, ao novo modelo de acumulação flexível. As organizações passam a valorizar mais os trabalhadores com posicionamento crítico, criativo e pensante para lidar com o novo mercado, trabalhadores que saibam identificar e resolver os problemas, além de ser capazes de trabalhar em equipe (CARMO, 2015).

No período da reestruturação do modelo capitalista na década de 1970, no qual a acumulação do capital passa a ser denominada de flexível, as instituições escolares passam a agregar novas atividades. De acordo com Alberto (2005), as escolas passam a ser vistas como responsáveis pela baixa qualificação da População Economicamente Ativa (PEA). Decorrência disso é o crescimento limitado das indústrias, o que obrigou as escolas a apresentarem novas formas de uma educação contínua. A educação passa a ser vista, então, com dois conceitos distintos: como promotora do desenvolvimento e elevação dos padrões de qualidade de vida, bem como a causadora de atraso e pobreza na mesma sociedade.

Nota-se que, a partir da implantação do neoliberalismo, a educação profissional

\begin{abstract}
passa a ser investida de novas funções voltadas para a formação de um trabalhador com um novo perfil. Assim, qualificar, requalificar, atualizar e reprofissionalizar passam a ser considerados objetivos fundamentais, uma vez que o que se aprende não é o suficiente para sempre. Como a realidade está em constante mutação, necessário se faz que se esteja permanentemente em busca de novos conhecimentos para solucionar novos problemas (ALBERTO, 2005, p. 300).
\end{abstract}

Segundo os apontamentos de SENAI. DN (2011), a educação que estava associada apenas ao saber fazer, vigente até o fim do século 20, passa a ser ressignificada por novos paradigmas, entre os quais estão a flexibilização das ocupações, a integração dos setores de produção, a multifuncionalidade e a valorização dos saberes.

Seguindo os princípios apresentadas por SENAI. DN (2011), Steffen e Fischer (2008) apontam que a capacitação profissional deverá pautar-se em outros aspectos, como no desenvolvimento dos saberes dos trabalhadores em situações concretas no mundo do trabalho. Segundo Manfredi (1999), estes saberes a serem desenvolvidos irão munir o indivíduo de capacidade para lidar com problemas concretos durante o exercício de sua atividade dentro da empresa. De acordo com a autora, devem ser desenvolvidos o "saber fazer", "saber ser" e "saber agir". 
Comum aos autores Alves e Vieira (1995), Rocha-Vidigal e Vidigal (2012) e Steffen e Fischer (2008), o ideal da qualificação profissional enquanto possibilidade de permanência em determinado emprego é amplamente discutido em seus estudos. Os autores afirmam que a qualificação refletirá positivamente na sua nova capacidade produtiva, assim como suas preocupações com questões de cunho político, econômico e social, e refletirá diretamente na organização à qual ele se encaixa. Steffen e Fischer (2008) afirmam, ainda, que, ao atrelarem os conhecimentos teóricos e práticos da qualificação ao nível empresarial por meio de suas habilidades cognitivas, operacionais e comportamentais, eles terão a sua permanência facilitada nas empresas.

\section{Educação e empoderamento}

Surgido na década de 1970, segundo Romano e Antunes (2002), o termo empowerment (empoderamento) apresenta-se com uma abordagem de "dar poder" a determinada pessoa ou grupo. Ele apresenta-se com a entrega dos plenos direitos da cidadania, com a capacidade de um ator usar recursos econômicos, sociais, políticos e culturais para atuar no espaço público.

Díspares a este ideal da doação ou transferência de poder, Perkins e Zimmerman (1995 apud HOROCHOVSKI; MEIRELLES, 2007) tratam do empoderamento como um "um construto que liga forças e competências individuais, sistemas naturais de ajuda e comportamentos proativos com políticas e mudanças sociais"; aquele que se empodera é ativo no processo, não é um ser passivo, como apresenta Romano e Antunes (HOROCHOVSKI; MEIRELLES, 2007, p. 486).

Na explanação dos autores, o empoderamento aproxima-se do ideal de autonomia; o sujeito a "ser empoderado", assim como também diz Romano (2002), deve assumir o controle de seus próprios assuntos, deve assumir a sua própria vida, relacionando-se "à capacidade de os indivíduos e grupos poderem decidir sobre as questões que lhes dizem respeito" (HOROCHOVSKI; MEIRELLES, 2007, p. 486). Empoderar trata, portanto, de um processo por meio do qual os sujeitos terão voz, capacidade de ação, poder decisório e visibilidade.

Empoderamento pode ser definido, ainda, como um processo que envolve o respeito, a reflexão crítica e a participação, por meio do qual as pessoas passariam a ter acesso a recursos outrora desconhecidos (SOUZA; MOREIRA; BOURGUIGNON, 2014). Perkins e Zimmermam (1995) corroboram esse ideal, ao afirmarem que entendem ser de grande importância a participação ativa dos sujeitos nas decisões das organizações comunitárias. 
Tal processo conta basicamente com três níveis de ação, sendo o individual aquele que se relaciona com os sujeitos e suas potencialidades; o comunitário, o que presume uma ação do coletivo em prol de determinado objetivo e, por fim, o organizacional, o que envolver-se-á com os processos de decisão coletiva dentro das organizações (SOUZA; MOREIRA; BOURGUIGNON, 2014). Trata-se, portanto, segundo Perkins (2010), de um processo ativo individual, comunitário ou organizacional, no qual imperam a reflexão crítica e tomada de consciência que envolvem a tomada de decisão sobre recursos importantes. Sendo assim, reitera a importância do empoderamento no nível individual, uma vez que nesse processo os sujeitos poderiam superar seus medos e traumas e, por consequência, melhorariam sua qualidade de vida. Dentro do contexto social os sujeitos associados poderão transformar as situações desfavoráveis.

Sabendo-se que nenhum sujeito é (ou será) totalmente autônomo, é necessário compreender que, assim como afirmam Horochovski e Meirelles (2007) e Baquero (2012), o empoderamento individual será

a habilidade das pessoas de ganharem conhecimento e controle sobre forças pessoais, para agir na direção de melhoria de sua situação de vida. Diz respeito ao aumento da capacidade de os indivíduos se sentirem influentes nos processos que determinam suas vidas (HOROCHOVSKI; MEIRELLES, 2007, p. 176).

Direcionada pela socialização e autonomia, McCowan (2015) argumenta que a educação é necessária, apresentando a linguagem, os conceitos, conhecimentos e habilidades necessários para a vida em sociedade. É necessária, também, considerando que faz os sujeitos críticos para "fazer escolhas sobre as nossas próprias vidas, em função da necessidade de estarmos cientes de que há pontos de vista e modos de vida distintos" (MCCOWAN, 2015, p. 29). O autor assegura que a educação é de extrema importância, pois possibilita melhor compreensão do mundo e de nós mesmos. A compreensão mais profunda do mundo aumenta a capacidade de ação dos sujeitos, sendo tal ação fator fundamental para a transformação da realidade social.

Alberto (2005) reitera a noção de que a educação profissional deve, então, despertar a autonomia intelectual e o pensamento crítico dos trabalhadores. No Encontro Nacional de Estudos do Trabalho (1999), Castioni diz que educação deve "ser entendida como uma construção social, cujos resultados não apenas se materializam no mercado de trabalho e em uma ocupação, mas ocorrem em outros espaços, como na família, no bairro, nas organizações sociais e políticas" (ENCONTRO NACIONAL DE ESTUDOS DO TRABALHO, 1999, p. 24). 
Portanto, a educação é um mecanismo que atuará como fator facilitador do processo de empoderamento dos sujeitos em determinada sociedade. Como, na maioria das vezes, tais sujeitos não tiveram a oportunidade de estar em um ambiente de educação formal ou estão em desvantagem dos mais variados recursos e bens sociais (BARBOSA; DELUIZ, 2008), são necessárias as intervenções externas de indivíduos, organizações ou do próprio governo, com projetos que objetivem o combate à exclusão e a promoção de direitos, em vistas de transformar a vida de pessoas e comunidades.

Necessário faz-se salientar que

nem o governo, nem as agências (e nem as ONGs) empoderam as pessoas e as organizações; as pessoas e as organizações se empoderam a si mesmas. O que as políticas e as ações governamentais podem fazer é criar um ambiente favorável ou, opostamente, colocar barreiras ao processo de empoderamento (ROMANO; ANTUNES, 2002, p. 12).

Órgãos governamentais, agências e ONGs, como relatado, criariam espaços e contextos que poderiam propiciar momentos que iniciariam e/ou dariam auxílio aos processos de empoderamento individuais. Tais entidades não são portadoras de uma fórmula que empoderará automaticamente os sujeitos, elas contribuiriam com o desenvolvimento individual de cada ser (SOUZA; MOREIRA; BOURGUIGNON, 2014).

\section{Políticas públicas}

O Estado, na formatação atual, já passou por várias mudanças e adaptações às mais diversas conjunturas com as quais teve de lidar. Atualmente, segundo Montenegro Gómez (2002) e SEBRAE (2008), é função do Estado promover o bem-estar da sociedade. Para a garantia deste, faz-se necessária a criação de ações em uma rede de atuações que garanta o alcance deste objetivo final para um povo. Por meio das políticas públicas nas mais diversas áreas, como saúde, educação, segurança e meio ambiente, o Estado atuará visando ao bem-estar de todos.

As políticas públicas apresentam-se como ramo da ciência política por meio da qual pesquisadores independentes e estudiosos da área poderão entender, segundo Souza (2006), por que os governos optam por determinada ação perante a sociedade. Tudo que o aparato governamental faz ou opta por não realizar será formulado cientificamente.

As políticas públicas, segundo Picone e Novak (2014), são vistas como fator para amenizar as diferenças entre as classes sociais. Elas são as garantidoras das necessidades básicas dos cidadãos. As autoras ressaltam que estão em

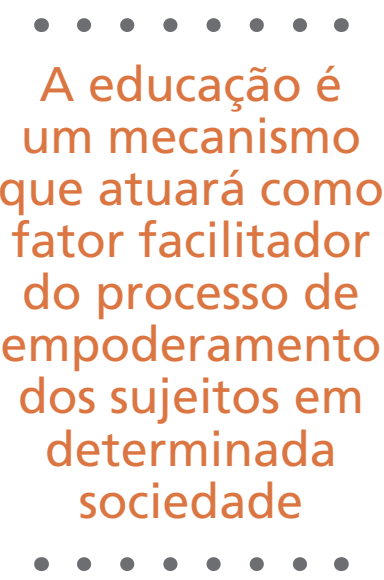

A educação é um mecanismo que atuará como fator facilitador do processo de empoderamento dos sujeitos em determinada sociedade 
constante movimento e adaptam-se de acordo com a sociedade, com o Estado e com o momento em que se enquadram, sendo que um de seus maiores desafios é a proposição de ações preventivas para o bem-estar social.

Em linhas gerais, como consenso entre SEBRAE (2008) e Souza (2006), uma boa política pública deverá: envolver vários atores e níveis de decisão; deixar claro o que determinado governo pretende fazer, faz e o que já fez; e ser uma ação intencional, com objetivos, e factível. Embora realizada a curto prazo, deverá apresentar reflexos a longo prazo e percorrer todos os processos posteriores à sua proposição, tal como a implementação, execução e avaliação.

\section{Políticas educacionais}

Tendo como referencial o citado na seção anterior a respeito das políticas públicas, é de fundamental importância debruçar-se sobre as políticas educacionais, levando-se em consideração que podem tratar-se daquilo que dado governo faz ou pode deixar de fazer pela educação de determinada sociedade. Sendo a educação um conceito extremamente amplo para tratar-se de suas políticas, pode-se dizer que as políticas públicas educacionais tratarão de ações, programas e projetos que envolvam as questões escolares, ou seja, tais políticas tratam-se da educação escolar formal (OLIVEIRA, 2010).

Ao restringir as políticas educacionais à educação escolar, é necessário esclarecer que a educação possui várias formas de apropriação nos mais diversos meios: escolas, igrejas, famílias, ruas, teatro etc. O recorte feito da educação escolar refere-se ao processo de ensino-aprendizagem realizado por um sistema delimitado por determinada política pública que utiliza um ambiente próprio para o fazer educacional; um ambiente no qual se articularão comunidade, professores, pais, alunos, servidores e o próprio Estado (OLIVEIRA, 2010).

De acordo com as informações do Instituto Nacional de Estudos e Pesquisas Educacionais Anísio Teixeira (Inep) (INEP, 2006, p. 165), as políticas educacionais "fazem parte do conjunto de políticas públicas sociais, expressão da ação (ou não-ação) social do Estado e que têm como principal referente a máquina governamental no movimento de regulação do setor de educação".

Entre as ferramentas políticas da educação, a Lei de Diretrizes e Bases da Educação Nacional (LDB) é a maior normativa que todas as organizações de ensino devem seguir, sendo que ela tem como princípio e finalidade que

a educação, dever da família e do Estado, inspirada nos princípios de liberdade e nos ideais de solidariedade humana, 
tem por finalidade o pleno desenvolvimento do educando, seu preparo para o exercício da cidadania e sua qualificação para o trabalho (BRASIL, 2015, p. 25).

Além da legislação aqui citada, vale lembrar que o sistema educacional se reinventa e se adapta a todo instante, o que confere, constantemente, às políticas educacionais, novas legislações, propostas e programas. Exemplo disso são os planos nacionais já em vigor, como o Plano Nacional de Educação (PNE), o Plano Nacional de Pós-Graduação, os Planos Nacionais de Desenvolvimento, entre outros (INEP, 2006).

Atualmente, entre as políticas educacionais, destaca-se a educação profissional como estratégia para o desenvolvimento tecnológico do país. A política nacional (BRASIL, 2004) aponta que as políticas para a educação devem comprometer-se com o desenvolvimento justo, igualitário e sustentável; o documento afirma que o pilar de tais políticas deve ser o social: o governo deve assumir um compromisso com a maioria da sociedade para defender os anseios públicos.

As políticas de educação profissional devem, também, segundo o mesmo documento (BRASIL, 2004), mobilizar a sociedade em favor do crescimento, utilizando-se das capacidades técnicas, empreendedoras e criadoras de seu povo. Estas capacidades serão visualizadas e utilizadas a partir da educação e do crédito aos pequenos empreendedores e das políticas intersetoriais de trabalho, emprego e renda.

\section{Programa Pão Escola}

O Programa Pão Escola é um programa de governo da $\mathrm{PBH}$ que "visa à qualificação na área de alimento para estudantes da Rede Municipal de Ensino" (BELO HORIZONTE, 2011a). Este programa oferece cursos de qualificação na área de alimentos para jovens e adultos com idade acima de 16 anos que estejam regularmente matriculados nas modalidades de ensino da EJA e Floração, preparando-os para uma melhor oportunidade no sistema de produção atual.

O presente programa é normatizado pela Portaria Conjunta SMED/SMASAN/SMATE n. 001/2011, na qual reza a associação de três secretarias para o desenvolvimento efetivo do programa, sendo elas: Secretaria Municipal de Educação (SMED), Secretaria Municipal Adjunta de Segurança Alimentar e Nutricional (SMASAN) e a Secretaria Municipal Adjunta de Trabalho e Emprego (SMATE).

A SMASAN, responsável direta pela oferta dos cursos do presente programa, é uma secretaria adjunta da Secretaria Municipal de Políticas Sociais (SMPS),

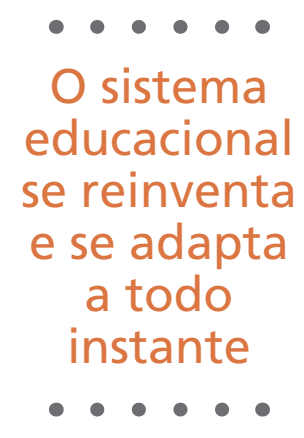
educacional se reinventa se adapta a todo $\ldots$ 
que se divide em oito eixos de atuação. A proposta do programa enquadra-se no eixo Geração de emprego e renda - qualificação profissional, que, por meio do programa Melhor Emprego, tem por objetivo

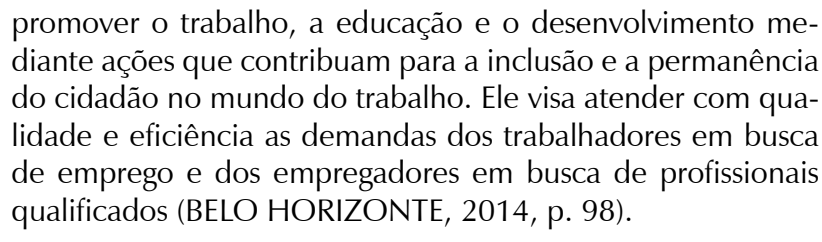

Tendo como objetivo a formação da mão de obra destes jovens para a sua inserção no mercado de trabalho, o PPE oferta cursos como: "Auxiliar de Panificação, Auxiliar de Confeitaria, Confeitaria Caseira, Auxiliar de Cozinha, Salgados \& Pizzas e Processamento Artesanal de Frutas" (BELO HORIZONTE, 2015a). Estes cursos qualificam os alunos e facilitam sua entrada no mercado, uma vez que muitos dos concluintes são encaminhados para vagas de emprego via Sistema Nacional de Emprego (SINE).

Surgido em 2000, o PPE acontece na

padaria Escola Nicola Calicchio que oferece estrutura, equipamentos e utensílios, ampliando as oportunidades de aprendizado dos alunos que frequentam o Mercado da Lagoinha com o objetivo de obter ou aprimorar a qualificação profissional (BELO HORIZONTE, 2016).

Ofertando cursos com as mais variadas durações, os momentos de formação são realizados por dois educadores que lidam diariamente com os alunos no contraturno de suas aulas de educação básica na escola. Os discentes participam de cursos de menor carga-horária - 20 horas-aula (Salgados e Pizzas e Panificação Aperfeiçoamento, por exemplo), cursos com média duração - 40 horas-aula (Confeitaria Caseira e Auxiliar de Cozinha), além dos cursos mais buscados que também possuem maior carga horária - 60 horas-aula Auxiliar de Panificação Industrial e Auxiliar de Confeitaria Industrial.

Durante as aulas, os discentes têm momentos distintos de formação, sendo eles aulas teóricas e práticas. Nas aulas teóricas os alunos recebem - com o auxílio de um professor municipal, que também coordena o Programa por parte da Secretaria Municipal de Educação - momentos de reforço em disciplinas da educação básica, como: Língua Portuguesa, Matemática, História, Geografia, entre outras. Nas aulas práticas os alunos lidam diretamente com a área de produção; eles executam as receitas previstas nas apostilas entregues nos primeiros dias de cursos. Nesses momentos, eles manipulam os insumos e massas, além de aprender a utilizar corretamente os maquinários industriais com os quais se depararão no mercado. 
Por meio dos relatórios disponibilizados no site do município, entre os anos de 2000 e 2012, foram formados 4.143 alunos (BELO HORIZONTE, 2012) provenientes das mais diversas regiões da capital, além de ser buscado por ambos os gêneros em proporções bem próximas: 53\% feminino, 47\% masculino (BELO HORIZONTE, 2011b). O perfil etário dos discentes segue um padrão com baixos níveis de desvio ao longo dos anos de execução, girando em torno de 55\% com idade entre 16 e 30 anos, 30,9\% entre 31 e 45 anos e $14 \%$ com 46 anos ou mais.

Ao aprofundar a análise dos relatórios anuais da instituição, observa-se, porém, algumas divergências de dados: a partir do ano de 2013, são contabilizadas apenas as vagas disponibilizadas para capacitação, não sendo possível encontrar o número de alunos concluintes; no relatório do ano citado (BELO HORIZONTE, 2013) é descrita a oferta de 575 vagas por meio do programa. No documento oficial do ano de 2014 (BELO HORIZONTE, 2014), é feita alusão ao ano anterior - 2013 - com um quantitativo superior ao apresentado no relatório do referido ano; o valor de 575 vagas antes indicado é elevado para 600 no relatório de 2014; dentro do mesmo documento a instituição apresenta ainda o quantitativo de 900 vagas disponibilizadas no ano. No ano de 2015, foram ofertadas 1.275 vagas no Programa, e no ano de 2016, foram abertas 1.125, conforme afirma a Prefeitura Municipal de Belo Horizonte ([201-]).

Debruçando-se ainda nos dados relativos às vagas, é possível observar que o programa teve nos anos de 2013, 2014 e 2015 uma taxa elevada no que se refere à desistência dos alunos de iniciar o programa de qualificação: de acordo com os relatórios, cerca de $43,7 \%$ dos discentes matriculados ao menos começaram os cursos. Do total de alunos que frequentaram, 75,3\% chegaram a concluir as aulas e serem certificados posteriormente (BELO HORIZONTE, 2013, 2014, 2015b).

No ano de 2011, em reconhecimento aos benefícios desta política pública para a população belo-horizontina, o programa recebeu o prêmio "Cidade da Oportunidade", promovido pela Cúpula Global de Empregabilidade Juvenil da Organização das Nações Unidas (ONU) (BELO HORIZONTE, 2012).

\section{Análise do Programa Pão Escola}

Por meio dos conceitos e das informações apontados pelos autores ao longo do trabalho, entende-se a importância de uma formação profissional para os trabalhadores na sociedade atual que, muito além da dimensão técnica, conceitual e de resposta às demandas do capitalismo, dê-lhes autonomia e desenvolva seu pensamento crítico. Por meio de políticas públicas ofertadas 
pelos governos (federal, estadual e municipal) que favoreçam a elevação da escolaridade da força de trabalho de dada localidade, os trabalhadores poderão entrar no processo de empoderamento e, a partir disso, tornarem-se agentes potenciais para impulsionar o desenvolvimento local, regional ou nacional de forma uniforme e igualitária, como apresenta a política nacional (BRASIL 2004).

Os ideais discutidos ao longo do texto apontam para um caminho comum: a formação da força de trabalho da sociedade atual pode e deve ser tratada com extrema importância para que, acima de tudo, forme cidadãos com potencial para serem pensadores, críticos e autores de suas próprias vidas (CARMO, 2015; MANFREDI, 1998; ROCHA-VIDIGAL; VIDIGAL, 2012; ROMANO, 2002), indo contra o pensamento capitalista de apenas dar uma resposta ao modelo de acumulação atual e demanda do mundo do trabalho.

A PBH oferta à população belo-horizontina a oportunidade de participar de cursos de qualificação profissional na área de Alimentação, os quais projetam os trabalhadores com maior facilidade no mundo do trabalho, essência primordial do programa. Tal recurso pode ser visto como ferramenta da gestão municipal que formará trabalhadores para suprir as demandas ditadas pelo mundo do trabalho.

A própria Portaria que institui o programa em nenhum momento levanta questões sobre a busca pelo empoderamento dos alunos. Ao contrário do expectável, é de um tecnicismo absoluto, meramente enumerando as atribuições de cada um dos órgãos parceiros e abrindo mão da imposição de diretrizes que tivessem por objetivo a busca pela autonomia dos estudantes (HOROCHOVSKI; MEIRELLES, 2007; ROMANO, 2002).

Uma análise dos itens de responsabilidade de cada parceiro demonstra o ideário de formação de mão de obra para uma sociedade capitalista, retomando um ciclo de geração de trabalhadores para, simplesmente, trabalhar. Como exemplos desta afirmação, os itens abaixo são especialmente esclarecedores:

Uma análise dos itens de responsabilidade de cada parceiro demonstra o ideário de formação de mão de obra para uma sociedade capitalista
Art. $3^{\circ}$ Competirá à Secretaria Municipal Adjunta de Segurança Alimentar e Nutricional (SMASAN), por meio do Mercado da Lagoinha:

[...] XI - elaborar, imprimir e distribuir as apostilas específicas dos cursos de qualificação;

[...] XIII - avaliar e conferir a certificação dos estudantes;

Art. $4^{\circ}$ Competirá à Secretaria Municipal de Educação (SMED):

[...] VIII - articular os conteúdos curriculares da Educação Básica, por meio de aulas e da apostila complementar, com os conteúdos específicos dos cursos de qualificação, bem como 
acompanhar a aprendizagem dos estudantes nessa articulação;

[...] IX - zelar pelo comportamento adequado e pela segurança dos estudantes no ambiente dos cursos;

Art. 5ํㅡㄹ Competirá à Secretaria Municipal Adjunta de Trabalho e Emprego (SMATE):

I. Cadastrar os estudantes do Programa "Pão-Escola" em um dos quatro postos de atendimento municipal do SINE.

[...] b) Após o cadastramento, os alunos participarão de ação formativa de apoio sobre 'Competências Básicas para o TrabaIho' e, a critério da Coordenação Pedagógica do 'Pão-Escola' essa ação, por se tratar de uma atividade socioeducacional, poderá ser contabilizada na carga horária do curso (BELO HORIZONTE, 2011a, p. 1-2).

Tais determinações demonstram claramente uma formação direcionada para o mercado, assim como expresso nos relatórios oficiais da $\mathrm{PBH}$, tais cursos visam atender, com qualidade e eficiência, as demandas dos empregadores (BELO HORIZONTE, 2014). Alijando-se da necessidade de uma formação dos alunos para a sua atuação autônoma, como argumentam Horochovsiki e Meirelles (2007), McCowan (2015) e Manfredi (1998), o PPE determina o ensino profissional vinculado às disciplinas da educação básica, para a formação do profissional, e o remete para os órgãos de cadastro de empregos (SINE).

Em nenhum momento o documento demonstra uma preocupação em apresentar aos alunos as possibilidades e diferentes visões de mundo que podem ter, ou mesmo como aquela formação pode ajudá-los a quebrar o paradigma do trabalho mão de obra e transformá-lo em trabalho-autonomia. A referida Portaria, única referência normativa disponibilizada sobre o programa, resume-se em descrever as atribuições administrativas que cada secretaria deverá desenvolver para garantir a avaliação, certificação e o encaminhamento para vagas de emprego, segundo Prefeitura Municipal de Belo Horizonte (2011a).

Apresentando os dados quantitativos ao longo dos anos de realização do programa e valorizando, por exemplo, apenas as vagas ofertadas a partir de dado momento, além de não possuir diretrizes para uma educação que vá além daquela meramente tecnicista, o presente programa deixa claro que está indo na contramão do pensamento de uma educação que impulsionará o empoderamento do sujeito. Os dados levantados evidenciam a importância dos valores numéricos de alunos formados, ou até mesmo das vagas disponibilizadas - não se preocupando nem mesmo em apresentar se foram preenchidas e quantos foram os alunos concluintes. Não são encontrados em momento algum dados relativos à dinâmica educativa, aos processos e às atividades que poderiam potencializar o perfil autônomo dos alunos. 
Ao apresentar ainda os dados, a partir do ano de 2013, apenas com o quantitativo de oferta das vagas, a instituição deixa em aberto a possibilidade de questionamentos por parte da academia científica, sociedade civil, ONGs, entre outros, da efetividade do Programa à sua própria proposta inicial de dar respostas às demandas dos empregadores por meio do mercado.

\section{Considerações finais}

Objetivando apresentar uma política pública em andamento no município de Belo Horizonte como ferramenta de gestão que tenha o potencial empoderador, o presente artigo, por meio dos dados referenciais e documentais levantados, apresentou o programa Pão Escola que, priorizando apenas uma resposta à demanda de mercado da sociedade atual, não pode encaixar-se nas conceituações levantadas e discutidas ao longo do estudo a respeito de uma formação profissional empoderadora.

A educação profissional tem sido alvo de discussão de estudiosos que desejam apresentá-la como forma de educação libertária

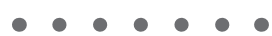

Cada vez mais buscada, de acordo com os autores apresentados, a educação profissional tem sido alvo de discussão de estudiosos que desejam apresentá-la como forma de educação libertária, que além de formar o sujeito com conhecimento técnico para o mundo do trabalho, forme, ao longo do processo, cidadãos conscientes de seus direitos e deveres. Assim como afirma Gallichio (2002), estas pessoas com formação adequada, inserção no mundo do trabalho e consciência crítica, trabalharão em prol de uma localidade mais desenvolvida, justa e igualitária.

O presente estudo, por se tratar de um artigo de revisão teórica e levantamento de dados documentais do programa encontrados no site da instituição, teve o acesso às informações aqui apresentadas restrito ao que a administração municipal opta por divulgar; devido a este fato, a pesquisa responde aos questionamentos iniciais do estudo, porém, sem informações mais detalhadas a respeito do programa, uma vez que os dados são escassos e ora divergentes.

Entende-se a necessidade do aprofundamento nos estudos acerca deste programa para avaliar, com ferramentas adequadas e pré-selecionadas, as dinâmicas educativas que estão postas, para que este recurso do município se torne um diferencial na sociedade atual, ofertando uma formação além das proposições técnicas, com um potencial empoderador de pessoas.

\section{Notas}

1É uma ação da Secretaria Municipal de Educação de Belo Horizonte, em parceria com a Fundação Roberto Marinho, destinada a jovens com idade 
de 15 a 19 anos, matriculados nas escolas municipais, que se encontram em situação de distorção idade-ano de escolarização, visando à conclusão do ensino fundamental (BELO HORIZONTE, 2015b).

${ }^{2}$ Proposta de concepção de Estado mínimo, não interventor na economia; um Estado que seja capaz de garantir a liberdade das pessoas, sendo o mercado o grande regulador da economia. Este ideal do Estado mínimo, em uma sociedade competitiva e consumista, propicia o funcionamento do mercado, que irá regular as ações dos indivíduos e promover o desenvolvimento econômico por meio da livre concorrência (BUFFON; COSTA, 2014).

\section{Referências}

ALBERTO, Maria Angélica. A noção de empregabilidade nas políticas de qualificação e educação profissional no Brasil nos anos de 1990. Trabalho, Educação e Saúde, Rio de Janeiro, v. 3, n. 2, p. 295-330, 2005.

ALVES, Edgard Luiz Gutierrez; VIEIRA, Carlos Alberto dos Santos. Qualificação profissional: uma proposta de política pública. Planejamento e Políticas Públicas, São Paulo, n. 12, jun./dez. 1995.

BARBOSA, Carlos Soares; DELUIZ, Neise. Qualificação profissional de jovens e adultos trabalhadores: o programa nacional de estímulo ao primeiro emprego em discussão.

Boletim Técnico do Senac, Rio de Janeiro, v. 34, n. 1, p. 51-63, 2008.

BAQUERO, Rute Vivian Ângelo. Empoderamento: instrumento de emancipação social? Uma discussão social. Revista Debates, v. 6, n. 1, p. 173-187, 2012.

BELO HORIZONTE. Prefeitura. Balanço 2012 prestação de contas. Belo Horizonte, 2012.

BELO HORIZONTE. Prefeitura. Balanço 2014 prestação de contas. Belo Horizonte, 2014.

BELO HORIZONTE. Prefeitura. Portaria conjunta SMED/SMASAN/SMATE n.

001/2011. Belo Horizonte, 2011a.

BELO HORIZONTE. Prefeitura. Programa Pão Escola. Belo Horizonte, 2015a.

Disponível em: <http://portalpbh.pbh.gov.br/pbh/ecp/noticia.do? evento=portlet> Acesso em: 11 maio 2015.

BELO HORIZONTE. Prefeitura. Relatório Pão Escola 2011. Belo Horizonte, $2011 \mathrm{~b}$.

BELO HORIZONTE. Prefeitura. Relatório Pão Escola 2013. Belo Horizonte, 2013.

BELO HORIZONTE. Prefeitura. Relatório Pão Escola 2015/1. Belo Horizonte, 2015b. 
BELO HORIZONTE. Prefeitura. Segurança alimentar e nutricional. Belo Horizonte, [201-]. Disponível em: <http://portalpbh.pbh.gov.br/pbh/ecp/comunidade.do?ev ento=portlet\&pldPlc=ecpTaxonomiaMenuPortal\&app=abastecimento\&tax=13128\&lan$g=p t \_B R \& p g=5740 \& \operatorname{taxp}=0 \&>$ Acesso em: 28 fev. 2016

BRASIL. Ministério da Educação. Legislação brasileira sobre educação. 3. ed. Brasilia, DF, 2015.

BRASIL. Ministério da Educação. Políticas públicas para educação profissional e tecnológica. Brasília, DF, 2004.

BUFFON, M.; COSTA, B. J. Do estado de bem-estar social ao neoliberalismo. Revista de Estudos Legislativos, Porto Alegre, ano 8, n. 8, p. 103-127, 2014.

CARMO, Jefferson Carriello do. Institutos federais de educação, ciência e tecnologia, no contexto das novas formas de trabalho e educação. Trabalho e Educação, Belo Horizonte, v. 24, n. 3, p. 91-103, 2015.

ENCONTRO NACIONAL DE ESTUDOS DO TRABALHO, 16., 1999, Belo Horizonte. Anais: avaliação de políticas públicas: modelos e usos da avaliação de impacto em programas de formação profissional. Belo Horizonte: ABET/Universidade Federal de Minas Gerais, 1999.

FISCHER, Maria Clara Bueno; FRANZOI, Naira Lisboa. Formação humana e educação profissional diálogos possíveis. Educação, Sociedade e Culturas, n. 29, p. 35-51, 2009.

FRIGOTTO, Gaudêncio. Ensino médio e técnico profissional: disputa de concepções e precariedade. Le Monde Diplomatique Brasil, São Paulo, v. 6, n. 68, p. 28-29, mar. 2013. Disponível em: <http://www. diplomatique.org.br/artigo.php?id=1384>. Acesso em: 16 maio 2016.

GALLICHIO, Enrique. Empoderamento, teorias de desenvolvimento e desenvolvimento local na América Latina. In: ROMANO, Jorge 0.; ANTUNES, Marta (Org.).

Empoderamento e direitos no combate à pobreza. Rio de Janeiro: ActionAid Brasil, 2002.

HOROCHOVSKI, Rodrigo Rossi; MEIRELLES, Giselle. Problematizando o conceito de empoderamento. In: SEMINÁRIO NACIONAL MOVIMENTOS SOCIAIS, PARTICIPAÇÃO E DEMOCRACIA, 2., 2007, Florianópolis. Anais... Florianópolis: UFSC, 2007.

IBGE. Pesquisa mensal de emprego. Rio de Janeiro, 2016. Disponível em: <ftp://ftp. ibge.gov.br/Trabalho_e_Rendimento/Pesquisa_Mensal_de_Emprego/Fluxograma/2016/ pme_201602fluxograma.pdf>. Acesso em: 11 mar. 2016.

INEP. Enciclopédia de pedagogia universitária: glossário. Brasília, DF, 2006.

MANFREDI, Silvia Maria. Trabalho, qualificação e competência profissional - das dimensões conceituais e políticas. Educação e Sociedade, Campinas, v. 19, n. 64, p. 13-49, 1999. 
MCCOWAN, Tristan. 0 direito humano à aprendizagem e a aprendizagem dos direitos humanos. Educar em Revista, Curitiba, n. 55, p. 25-46, 2015.

MONTENEGRO GÓMEZ, Jorge. Crítica ao conceito de desenvolvimento. Pegada Eletrônica, Presidente Prudente, n. 1, p. 20-32, 2002.

OLIVEIRA, Adão Francisco de. Políticas públicas educacionais: conceito e contextualização numa perspectiva didática. In: OLIVEIRA, Adão Francisco; PIZZIO, Alex; FRANÇA, George (Org.). Fronteiras da educação: desigualdades, tecnologias e políticas. Goiania: Ed. Puc Goiás, 2010. p. 93-99.

ORGANIZAÇÃO INTERNACIONAL DO TRABALHO. Tendencias mundiales del empleo 2012: prevenir una crisis mayor del empleo. Ginebra, 2012. Disponível em: <http://www.oitbrasil.org.br/sites/default/files/topic/employment/doc/ resumoget2012_763.pdf>. Acesso em: 13 de maio 2016.

PERKINS, D. Empowerment. In: COUTO, R. (Ed.). Purposes of political and civic leadership. Thousande Oaks: Sage, 2010. p. 207-219. Disponível em: <https:// my.vanderbilt.edu/perkins/le s/2011/09/25. Empowerment_chapter.penultimate_draft. doc>. Acesso em: 13 maio 2016.

PERKINS, D.; ZIMMERMAN, M. Empowerment theory, research and application. Amerincan Journal of Community Psychology, v. 23, n. 5, p. 569579, 1995. Disponivel em: <https://my.vanderbilt.edu/perkins/les/2011/09/empintro. proquest. pdf>. Acesso em: 4 ago. 2016.

PICONE, Eugênia Vianna; NOVAK, Eliete Maceno. Políticas públicas educacionais no Brasil. In: BONINI, Luci Mendes de Melo; CIANCIARULLO, Tamara Iwanow; PANHOCA, Ivone (Org.). Políticas públicas: estudos e casos. São Paulo: Ícone, 2014. p. 33-677.

ROCHA-VIDIGAL, Cláudia Bueno; VIDIGAL, Vinícius Gonçalves. Investimento na qualificação profissional: uma abordagem econômica sobre sua importância. Acta Scientiarum: human and social sciences, Maringá, v. 34, n. 1, p. 41-48, 2012.

ROMANO, Jorge 0. Empoderamento: recuperando a questão do combate à pobreza. In: ROMANO, Jorge 0.; ANTUNES, Maria (Org.). Empoderamento e direitos no combate à pobreza. Rio de Janeiro: Action Aid Brasil, 2002.

ROMANO, Jorge 0.; ANTUNES, Maria. Introdução ao debate sobre empoderamento e direitos no combate à pobreza. In: ROMANO, Jorge 0.; ANTUNES, Maria (Org.). Empoderamento e direitos no combate à pobreza. Rio de Janeiro: Action Aid Brasil, 2002. p. 5-8.

SEBRAE. Políticas públicas: conceitos e práticas. v. 7. Belo Horizonte, 2008. SENAI. DN. Pró-docente: curso de iniciação à docência na educação profissional e tecnológica. Brasília, DF, 2011.

SILVA, Mariléia Maria da. Inserção profissional de jovens: o circuito fechado da precarização. Trabalho e Educação, Belo Horizonte, v. 23, n. 3, p. 177-194, 2014. 
SILVA, Mariléia Maria da; JUNG, Pâmela Regina; VIEIRA, Letícia. O lugar do trabalho para jovens egressos do Consórcio Social da Juventude. Revista Cocar, Belém, v. 6, n. 12, p. 87-100, 2012.

SOUZA, Celina. Políticas públicas: uma revisão de literatura. Sociologias, Porto Alegre, ano 8, n. 16, p. 20-45, 2006.

SOUZA, C. G.; MOREIRA, D.; BOURGUIGNON, J. A. Aproximações entre participação e empoderamento em uma perspectiva emancipatória. Revista NUPEM, Campo Mourão, v. 6, n. 11, 2014.

STEFFEN, Euli Marlene; FISCHER, Maria Clara Bueno. Qualificação profissional do técnico industrial em plásticos. Cadernos de Educação, Pelotas, n. 31, p. 227-248, 2008. 